\title{
Pure Uterine Lipoma on 18FDG PET/CT: Rare But Easy to Diagnose
}

\author{
Maseeh U. Zaman ${ }^{1}$, Nosheen Fatima ${ }^{1}$, Wasim A. Memon ${ }^{1}$, Areeba Zaman ${ }^{2}$, Sidra Zaman ${ }^{3}$ \\ 1. Radiology, Aga Khan University Hospital, Karachi, PAK 2. Internal Medicine, Dr. Ruth K.M. Pfau Hospital, Karachi, \\ PAK 3. Radiology, Dow Medical College, Karachi, PAK
}

Corresponding author: Maseeh U. Zaman, maseeh.uzzaman@aku.edu

\begin{abstract}
Tumors of the uterus are extremely uncommon. Pure lipomas of the uterus are very rare, and only a few cases have been reported. We are presenting a case of a post-menopausal lady, a survivor of right breast cancer who had an 18 F-fluorodeoxyglucose positron emission tomography/computed tomography $\left({ }^{18} \mathrm{FDG}\right.$ $\mathrm{PET} / \mathrm{CT}$ ) for evaluation of a suspected right lung nodule. The scan was negative for hypermetabolic abnormality. However, a hypodense and non-metabolic lesion was seen in the fundus of the uterus. On subsequent hysterectomy, it was found to be a pure lipoma.
\end{abstract}

Categories: Obstetrics/Gynecology, Radiology, Oncology

Keywords: pure lipoma of uterus, lipomatous tumor of the uterus, 18-fdg pet/ct

\section{Introduction}

Lipomatous tumors of the uterus are very uncommon (incidence: $0.03 \%-0.25 \%$ ) [1] and were first described by Lobstein in 1816 [2]. Most reported cases have been of the mixed type containing varying amounts of smooth muscle and fibrous elements. Pure lipomas involving the uterine wall are exceedingly rare; the exact incidence is not known as only a few cases have been reported thus far in the literature [3]. Because of the pure fatty nature of the tumor, computerized tomography (CT) is considered the diagnostic modality [4]. In current oncological practice, F-18 fluorodeoxyglucose $\left({ }^{18} \mathrm{FDG}\right)$-based positron emission tomography and CT (PET/CT) has become an integral part of management. Lipomas consistently show a low ${ }^{18} \mathrm{FDG}$ uptake (standardized uptake value (SUV) < 2.0) [5], but current literature is silent about the features of a pure lipoma of the uterus using ${ }^{18} \mathrm{FDG}$ PET/CT imaging. We are presenting the first case of a pure uterine lipoma found on ${ }^{18}$ FDG PET/CT imaging of a postmenopausal breast cancer survivor.

Received 02/11/2019 Review began 03/15/2019 Review ended 03/25/2019 Published 03/27/2019

(c) Copyright 2019 Zaman et al. This is an open access article distributed under the terms of the Creative Commons Attribution License CC-BY 3.0., which permits unrestricted use, distribution, and reproduction in any medium, provided the original author and source are credited.

\section{Case Presentation}

Herein, we present the case of a 67-year-old female breast cancer survivor who had a right lumpectomy for ductal carcinoma in 2012. She was clinically asymptomatic. However, a recent CT scan of the chest revealed a subcentimeter soft tissue nodule in the lower lobe of the right lung which was not appreciable on previous CT lung window films (no soft images were available). It was considered a possible granuloma but an ${ }^{18} \mathrm{FDG}$ PET/CT was recommended for evaluation and surveillance of the nodule. The PET/CT was performed with $10.2 \mathrm{mCi}$ of ${ }^{18} \mathrm{FDG}$ after 60 -minute skull to mid-thigh images were acquired using a low-dose, non-contrast enhanced CT protocol. The scan showed no morphological or functional evidence of tumor in either breast or hypermetabolic nodal and no hepatic, adrenal, pulmonary, or bony metastases. There was a redemonstration of the subcentimeter ametabolic soft tissue nodule in the lower lobe of the right lung with minimal infiltrate in the right lung base. The uterine fundus revealed an ${ }^{18} \mathrm{FDG}$ non-avid hypodense area (Hounsfield unit (HU): -89.9) measuring $40 \times 30 \mathrm{~mm}$ (anteroposterior (AP) and transverse (TV) dimensions) without regional nodes (Figure 1). Based on the image characteristics, it was reported as a lipoma. An uneventful hysterectomy was performed after three weeks on request by the family, and the histopathology revealed a pure lipoma. 


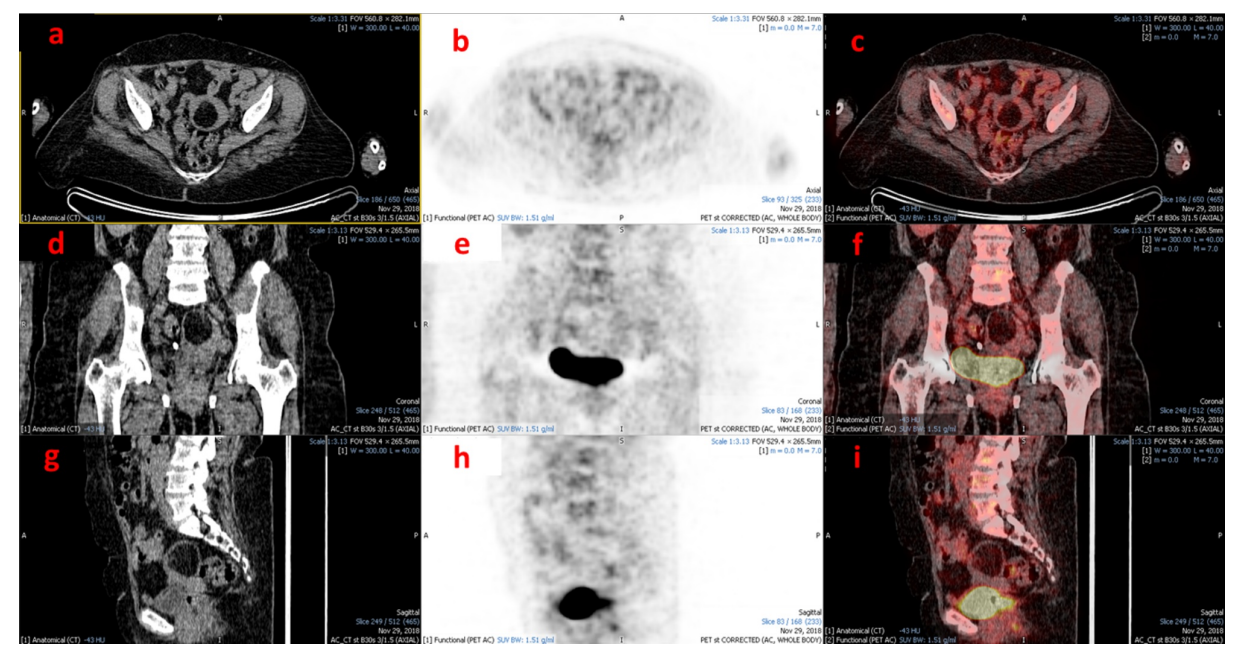

FIGURE 1: 18FDG PET/CT images (a-c: axial; d-f: coronal; g-i: sagittal) showing a well-defined hypodense area (Hounsfield unit (HU): -89.9) without metabolic activity in the uterine fundus

\section{Discussion}

A pure lipoma of the uterus is an exceedingly rare tumor and few cases have been published thus far. The first reported case of a pure uterine lipoma on preoperative ultrasound was published in 1979 [6] and the authors correctly identified the fatty nature of the tumor but incorrectly reported it as dermoid. The first case of a pure lipoma of the uterus identified on CT scan was reported in 1988 which had well-circumscribed and homogenously hypodense attenuation parameters (HU: -118) [7]. However, mixed uterine lipomas may mimic fibroid tumors depending upon the contribution of non-lipomatous tissue. Because of these peculiar features, a CT scan is considered as the imaging modality of choice for uterine pure lipomas. Lipomas (white fat tumors) are considered to have consistently low ${ }^{18} \mathrm{FDG}$ uptake in contrast to hibernomas (brown fat tumors), which are usually hypermetabolic, as they are thermogenic and rich in mitochondria [5]. Uterine tumors show a wide spectrum of ${ }^{18} \mathrm{FDG}$ uptake ranging from low uptake in benign tumors (some leiomyomas may have high uptake) to intense uptake in malignant neoplasms [8]. However, the literature is silent about ${ }^{18} \mathrm{FDG}$ PET/CT imaging of pure lipoma of the uterus. To the best of our research, this is the first case report revealing the ${ }^{18} \mathrm{FDG}$ PET/CT imaging features of a pure lipoma of the uterus.

Pure lipomas of the uterus are usually found in post-menopausal women and about $60 \%$ are intramural. They are usually asymptomatic but may present with symptoms like pain and bleeding, particularly if associated with uterine leiomyomas. On ultrasonography, these tumors have an echogenic center due to the fat and are avascular with a hypoechoic rim due to myometrium in the periphery [9]. On magnetic resonance imaging (MRI), a uterine lipoma would appear as a high signal on T1 and T2 sequences and show signal dropout on fat, thus confirming the diagnosis [9]. On CT examination, these are classically hypodense with a hyperdense periphery when they are intramural [7]. In this case report, the CT appearance of a pure lipoma of the uterus was also similar to the previous report with an ametabolic ( ${ }^{18} \mathrm{FDG}$ non-avid) appearance on PET images (hypodense and hypometabolic) as commonly observed in non-uterine pure lipomas. With the increasing use of ${ }^{18} \mathrm{FDG}$ PET/CT in oncology, there are high odds of finding more cases of pure uterine lipomas and these characteristic imaging features would help the reporting physicians to make a preoperative diagnosis with higher confidence.

\section{Conclusions}

A pure lipoma of the uterus is an exceedingly rare benign tumor, and this first case report depicting its appearance on ${ }^{18}$ FDG PET/CT imaging would certainly help the reporting nuclear physicians and radiologists to diagnose it with a high level of confidence.

\section{Additional Information}

\section{Disclosures}

Human subjects: Consent was obtained by all participants in this study. Conflicts of interest: In compliance with the ICMJE uniform disclosure form, all authors declare the following: Payment/services 
info: All authors have declared that no financial support was received from any organization for the submitted work. Financial relationships: All authors have declared that they have no financial relationships at present or within the previous three years with any organizations that might have an interest in the submitted work. Other relationships: All authors have declared that there are no other relationships or activities that could appear to have influenced the submitted work.

\section{References}

1. Loffroy R, Nezzal N, Mejean N, Sagot P, Krausé D: Lipoleiomyoma of the uterus: imaging features . Gynecol Obstet Invest. 2008, 66:73-75. 10.1159/000127409

2. Brandfass RT, Everts-Suarez EA: Lipomatous tumors of the uterus; a review of the world's literature with report of a case of true lipoma. Am J Obst Gynecol. 1955, 70:359-67. 10.1016/S0002-9378(16)37680-3

3. Chandawale S, Karia KM, Agrawal NS, Patil AA, Shetty AB, Kaur M: Uterine lipoleiomyoma and lipoma: A rare unique case report with review of literature. Int J Appl Basic Med Res. 2018, 8:193-95. 10.4103/ijabmr.IJABMR 11917

4. Chu CY, Tang YK, Chan TS, Wan YH, Fung KH: Diagnostic challenge of lipomatous uterine tumors in three patients. World J Radiol. 2012, 4:58-62. 10.4329/wjr.v4.i2.58

5. Kim JD, Lee HW: Intense uptake on F18-FDG PET/CT. Nucl Med Mol Imaging. 2012, 46:218-22. 10.1007/s13139-012-0150-z

6. Houser LM, Carrasco CH, Sheehan CR Jr: Lipomatous tumour of the uterus: radiographic and ultrasonic appearance. Br J Radiol. 1979, 52:992-93. 10.1259/0007-1285-52-624-992

7. Jacobs JE, Markowitz SK: CT diagnosis of uterine lipoma. AJR Am J Roentgenol. 1988, 150:1335-56. 10.2214/ajr.150.6.1335

8. Kitajima K, Murakami K, Kaji Y, Sugimura K: Spectrum of FDG PET/CT findings of uterine tumors . AJR Am J Roentgenol. 2010, 195:737-43. 10.2214/AJR.09.4074

9. Pathak V, Sukheeja D, Singh RK: Uterine intramural lipoma: a benign but rare entity . Med J DY Patil Univ. 2017, 10:384-85. 10.4103/0975-2870.213931 